\title{
Distal Radial Epifizin Manyetik Rezonans Görüntülemesi: Yaşayan Bireylerde Adli Yaş Tayini
}

\section{Magnetic Resonance Imaging of The Distal Radial Epiphysis: Forensic Age Estimation in Living Individuals}

\author{
Ŏguzhan Ekizoğlu', Elif Hocaoğglu ${ }^{2}$ Ercan İnci ${ }^{2}$ \\ ${ }^{1}$ Tepecik Eğitim ve Araştırma Hastanesi, Adli Tip Birimi, İzmir \\ ${ }^{2}$ Bakırköy Dr. Sadi Konuk Eğitim ve Araştırma Hastanesi, Radyoloji Kliniği, İstanbul
}

\begin{abstract}
Özet
Amaç: Adli yaş tayini özellikle çocuklar ve genç erişkinler başta olmak üzere cezai ve sivil hakların belirlenmesinde çok önemlidir. Günümüze kadar tanımlanan ve güvenilirliği ve geçerliliği kabul edilmiş metotlar olsa da özellikle radyasyon maruziyetine dayalı etik tartışmalar önemlidir. Son y1llarda kişileri radyasyon maruziyetinden koruyan manyetik rezonans görüntüleme (MR) kullanımı denenmektedir. Bu çalışmanın amacı distal radial epifizin MR ile analizinin yaş tahmininde kullanılabilirliğini araştırmaktır.

Gereç ve Yöntem: Çalışmada 12-20 yaş grubuna ait 198 el bileği MR retrospektif olarak değerlendirilmiştir. Çalışmamızda daha önce Dvorak tarafindan profesyonel sporcuların değerlendirmesinde kullanılan distal radial epifiz MR değerlendirme yöntemi kullanılmiştır.

Bulgular: Tespit edilen ilk görülme yaşları kadınlarda evre 2 de 13, evre 3 ve 4 de 14, evre 5 de 15 ve evre 6 da 16 yaştır. Erkeklerde ise evre 2 ve 3 de 14 , evre 4 'te 15 , evre 5 ve 6 'da 16 yaştır.

Sonuç: Distal radius epifizinin Dvorak metodu ile analizi noniyonize bir yöntem olarak 13-16 yaşlarda ilk görülme yaşları açısından başarılı olmakla birlikte 17 ve 18 yaşlar için çalışma popülasyonumuzda veri sunamamıştır. Gerek yöntemin gerekse çalışma popülasyonlarının genişletildiği çalışmalara ihtiyaç vardır.

Anahtar Kelimeler: Yaş Tayini; Distal Radial Epifiz; Manyetik Rezonans Görüntüleme.
\end{abstract}

\begin{abstract}
Objective: Determining forensic age is very important in legal and civil rights cases, particularly in those involving children and young adults. Although methods for performing such estimates have been developed and their reliability has been demonstrated, radiation exposure has become controversial. In recent years, magnetic resonance imaging (MRI) has been used in an attempt to protect patients from radiation exposure. The aim of this study is to evaluate usefulness of staging via magnetic resonance imaging of distal radial epiphysis in age estimation.

Materials and Methods: In this study, 198 hand-wrists (patient age, 12-20 years) were retrospectively evaluated with MRI using the "distal radial epiphysis assessment method," which was used previously by Dvorak to evaluate professional sportsmen.

Results: The ages at which bony fusion occurs have been identified. Females reach stage 2 at 13 years, stages 3 and 4 at 14 years, stage 5 at 15 years, and stage 6 at 16 years, whereas males reach stages 2 and 3 at 14 years, stage 4 at 15 years, and stages 5 and 6 at 16 years.

Conclusion: Although the non-ionizing Dvorak method of analyzing the distal radius epiphysis was successfully used for subjects aged 13-16 years, it failed to provide data about 17 and 18-year-olds. Thus, we need to develop a method for this age group and expand the applicable population.
\end{abstract}

Keywords: Age Estimation; Distal Radial Epiphysis; Magnetic Resonance Imaging.

\section{Giriş}

Yasaların uygulanmasında bildirilen yaşın gerçekliği ile ilgili şüphe bulunan ya da doğum kaydı bilinmeyen bireylerin yaşlarının belirlenmesi önemli bir ihtiyaçtır (1-3). Bireylerin cezai sorumluluğun değerlendirilmesi aşamasında kişinin hangi yaş grubunda olduğunun saptanması belirlenmesi öncelikli başlıklardandır (2-4). Hukuk sistemlerindeki farklılıklar ülkeler arasındaki hukuki değerlendirmede farklı yaş sınırlarını da ortaya

Sorumlu Yazar: Uzm. Dr. Oğuzhan Ekizoğlu

Tepecik Eğitim ve Araştırma Hastanesi, Adli Tip Birimi, İzmir

E-mail:drekizoglu@gmail.com

Geliş:28.03.2017 Düzeltme:07.04.2017 Kabul:09.04.2017 çıkarmaktadır. Çoğunlukla 10-21 yaş sınırları arasında değişkenlik göstermekte, en sık 14, 16, 18 ve 21 yaşlar eşik sınırlar olarak dikkat çekmektedir (3-5). Türkiye'de 12,15 ve 18 yaş sınırları kullanılmaktadır. Diğer taraftan mültecilik, sığınma talebi, evlilik yaşı, evlatlık değerlendirmeleri kapsamında, yaş tayini sivil hakların belirlenmesinde kritik bir rol oynar $(3,4,6)$. Bu noktada özellikle tüm dünyada son yıllarda adli yaş tayini açısından mültecilik ve sığınma talebi önemli bir başlıktır (6). Birleşmiş Milletler Mülteciler Yüksek Komiserliği (UNHCR) raporuna göre 2014 yılında tüm dünyada 866 bin sığınma başvurusu yapılmış ve bu rakam önceki döneme göre $\% 45^{\prime}$ lik bir artışı göstermiştir (7). Aynı 
raporda bölgelere göre sığınmacı sayısı ve artış oranlarının incelenmesinde Avrupa'da 714.300 (\%45 artış), 570.800 Avrupa Birliği ülkeleri (\%47 artış) ve Güney Avrupa 170.700 (\%95 artış), Kuzey Amerika 134.600 (\%42 artış) sı̆̆ınma başvuruları bildirilmiştir. 173.100 başvuru ile Almanya ilk sırada iken sırasıyla 121.200 başvuru ABD, Türkiye $(87,800)$, İsveç $(75,100)$, ve İtalya $(63,700)$ bulunmaktadır. Veriler mültecilik ve sığınma taleplerinin artan sayıda yaş tayini değerlendirmesini de beraberinde getireceğini göstermektedir. Bu durum doğum kayıtlarının bulunmaması faktörünün yanı sıra resmi görevlilerin kişilerin yaşının güvenilir olmadığına dair bildirimlerine de dayanmaktadır. Birleşik Krallık Mülteciler Konseyi 2015 istatistik raporunda 2014-2015 yılları ikinci çeyrekleri arasında 2564 sığınma başvurusu içinde resmi görevliler tarafindan 281 şüpheli yaş olgusu bildirilmiştir (8).

Günümüzde yaşayan bireylerin yaş tayini için birçok yöntem üzerinde çalışılmakla birlikte "Alman Adli Tıp Derneği Adli Yaş Tayini Birimi” tarafından tavsiye edilen yaklaşım "antropometrik ölçümler ile birlikte fiziksel değerlendirme ve seksüel gelişimin değerlendirilmesi; sol elin ve dişlerin radyolojik incelenmesi, eğer elin iskelet gelişimi tamamlamış ise ek olarak klavikulaların değerlendirilmesi" olarak bildirilmektedir (9). Uluslararası Adli Tıp Akademisinin (IALM) bir şubesi olan Avrupa Adli Antropoloji Cemiyeti (FASE), yaşayan genç erişkin bireylerin yaş tayinine yönelik tavsiyesi "fizik muayene ve Tanner evrelemesi, radyolojik olarak Greulich and Pyle Atlası and Tanner-Whitehouse ile el-el bileği analizi, Diş gelişimi için Demirjian metodu ve Mincer metodu ile klavikula mediyal ossifikasyon değerlendirmesi” şeklindedir (3).

Sonuç olarak önerilen yöntemlerin kombine kullanımında amaç yaşın doğru bir şekilde tespit edilmesini sağlamaktır. İskelet sistemi yaşın tespiti için temel araştırma noktası olmaya devam etmektedir ve en sik kullanılan metot sol el-el bileği röntgenlerinin Greulich ve Pyle Atlası (10) ve Tanner ve Whitehouse (11) yöntemi ile değerlendirilmesidir. Geçerliliği ve güvenilirliği en çok kabul gören yöntemler olmasına karşın farklı popülasyonlarda yapılan çalışmalarda hata payları bildirilmiştir (3). Bu durum iskelet gelişimi etkileyen patolojik durumlar, sosyoekonomik durum ve etnik kökenden kaynaklandığı bildirilmektedir.

Son yıllarda özellikle çocuk yaş grubunda yapılan yaş tayinine yönelik radyolojik incelemeler radyasyon maruziyeti açısından etik bir kaygıdır. Bu noktada bazı araştırmacilar USG incelemeleri ile distal radius (12), iliak krest (13), distal fibula (14) ve mediyal klavikula (15) ve MR ile mediyal klavikula (16-19), distal tibia ve kalka- neus (20-22), proksimal tibial epifiz $(23,24)$, iliak krest (25), el-el bileği (26-33) ve distal femur (34-36) temelli farklı iskelet alanlarını ele alan çalışmalar yapmışlardır. $\mathrm{Bu}$ doğrultuda el bileği MRI değerlendirmesine dayanan farklı metodolojiler uygulanmıştır. Dvorak $(26,27)$, Tomei $(30,31)$ ve Schmidt (33) tarafindan farklı metodolojiler tanımlanmış olup araştırma popülasyonlarının çoğunlukla sporcular olduğu izlenmiştir.

$\mathrm{Bu}$ çalışmanın amacı Dvorak tarafindan tanımlanan distal radial epifizin MR değerlendirilmesi sonucu elde edilen verilerin analizidir.

\section{Gereç ve Yöntem}

Bu çalışmada Bakırköy Dr. Sadi Konuk Eğitim ve Araştırma hastanesinde travmatik endikasyonlar nedeniyle Ocak 2013- Haziran 2015 tarihleri arasında çekilen 12-20 yaş grubuna ait 198 el bileği MR retrospektif olarak değerlendirildi. Çalışmaya dahil edilen hastaların medikal kayıtlarında gelişimsel iskelet hastalığı ve endokrin patolojiler ve MR değerlendirmesinde iskelet patolojisi dışlama kriteri olarak ele alındı ancak herhangi bir patolojik değişim tespit edilmedi.

Tüm olgular bir radyolog (R1) tarafindan değerlendirildikten sonra intraobserver güvenilirlik için tüm olgular R1 tarafından ilk değerlendirme sonuçları ve yaş bilgilerine kör olacak şekilde tekrar değerlendirildi. İntraobserver değerlendirme için Cohen kappa non-parametrik testi kullanıld1.

Distal radius epifizinin değerlendirilmesinde Dvorak et al $(26,27)$ tarafından tanımlanmış 6 evreli sistem kullanılmıştır. Evreleme metodu şu şeklidedir,

\section{I: Füzyon tamamen yok (Resim 1)}

II: Erken füzyon: epifizde minimal hiperintensite (Resim 2)

III: Radial kesit alanında trabeküler füzyon \%50'den düşük (Resim 3)

IV: Radial kesit alanında trabeküler füzyon \%50'den yüksek (Resim 4)

V: Rezidüel epifiz hattı her bir kesitte 5 mm'den küçük (Resim 5)

VI: Füzyon tamamlanmış (Resim 6)

İstatistiksel analizler için Statistical Package for the Social Sciences (SPSS) (version 17; SPSS, Chicago, IL, USA) kullanılmıştır. Evreleme aralıkları için ortalama, median, standart deviasyon, minimum ve maksimum değerler ile üst-alt sınırlar hesaplanmıştır. Yaş ve evre arasında Spearman's korelasyon analizi, cinsiyetler arası fark için Mann-Whitney U-testi uygulandı ve $p$ değeri $<0.05$ anlamlı kabul edildi. 


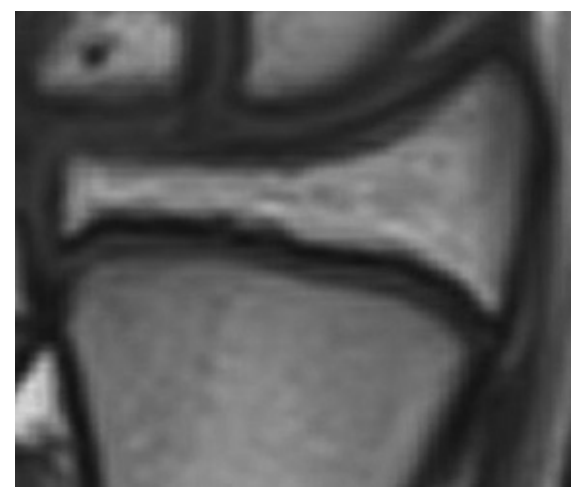

Resim 1. Distal radial epifizin manyetik rezonans görüntüsü: füzyon yok.

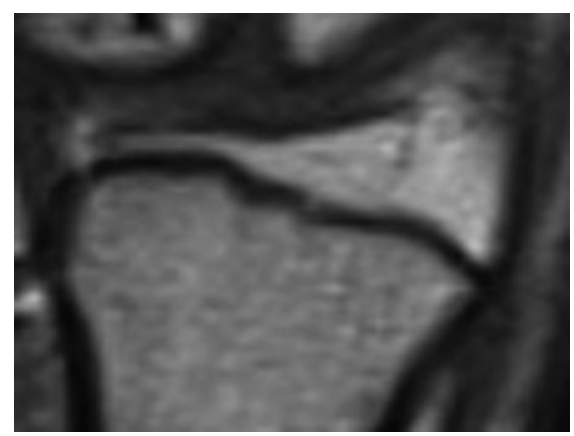

Resim 2. Distal radial epifizin manyetik rezonans görüntüsü: erken füzyon.

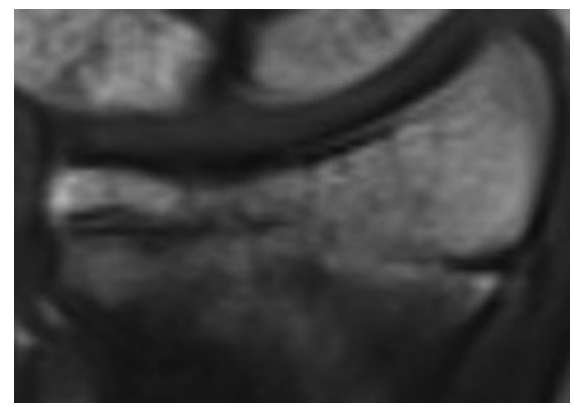

Resim 3. Distal radial epifizin manyetik rezonans görüntüsü: trabeküler füzyon \%50’nin altında.

İntraobserver analiz için Cohen $\kappa$ testi uygulandı ve sonuçlar Altman (37) sınıflamasına göre yorumlandı.

- $\kappa<0.20$ : kötü

- $\kappa=0.21-0.40$ : adil

- $\kappa=0.41-0.60$ : orta

- $\kappa=0.61-0.80$ : iyi

- $\kappa=0.81-1.00$ : çok iyi

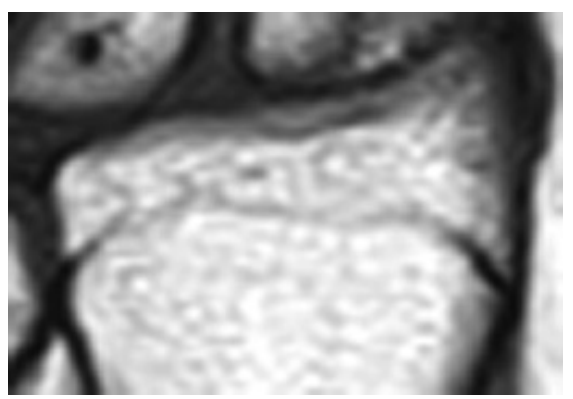

Resim 4. Distal radial epifizin manyetik rezonans görüntüsü: trabeküler füzyon $\% 50$ 'nin üstünde.

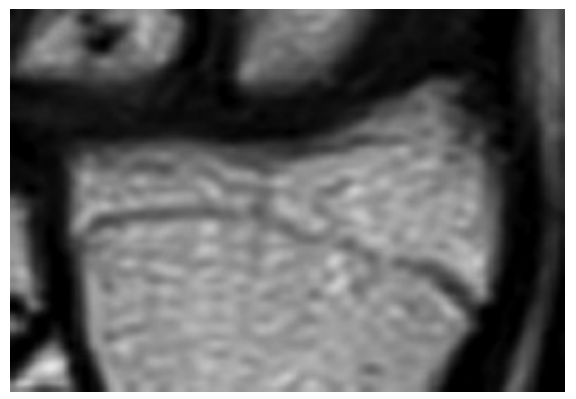

Resim 5. Distal radial epifizin manyetik rezonans görüntüsü: 5 mm'den daha küçük rezidüel fizis.

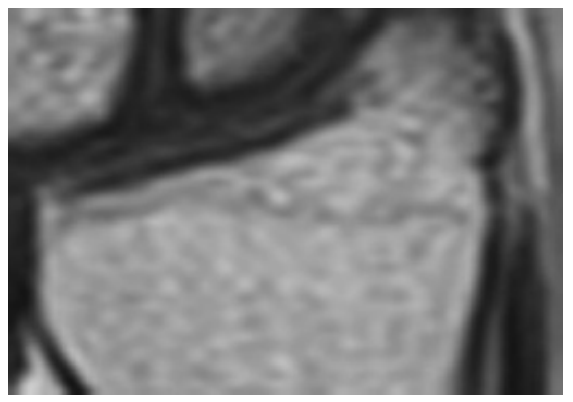

Resim 6. Distal radial epifizin manyetik rezonans görüntüsü: füzyon tamamlanmış.

\section{Bulgular}

Çalışmamızda 198 hastaya ait el bileği MRI değerlendirildi (120 kadın, 78 erkek, 12-20 yaş). Kadınlarda ortalama yaş $17.13 \pm 4.3$ ve erkeklerde $17.34 \pm 4.6$ olarak tespit edildi. Yaşlara göre her iki cinsiyet için olguların dağılımı tablo 1'de sunulmuştur. Evrelere göre cinsiyetler aras1 farklılıklarının karşılaştırılmasında anlamlı farklılık saptanmadi. Yaş ve evreler arasında Spearman's korelasyon 
analizi sonucunda anlamlı korelasyon saptanmıştır (tüm olgular: rho $=0.796, p<0.01$; erkek: $0.847, p=0.001$; kadin: rho=0.821, $p<0.01)$.

Tablo 1. Erkek ve kadın olguların yaş dağılımı

\begin{tabular}{|l|l|l|}
\hline Yaş (yıl) & Kadın & Erkek \\
\hline 12 & 4 & 5 \\
\hline 13 & 6 & 4 \\
\hline 14 & 11 & 10 \\
\hline 15 & 14 & 5 \\
\hline 16 & 14 & 13 \\
\hline 17 & 22 & 12 \\
\hline 18 & 24 & 17 \\
\hline 19 & 19 & 9 \\
\hline 20 & 6 & 3 \\
\hline Toplam & 120 & 78 \\
\hline
\end{tabular}

Evreler için elde edilen istatistiki veriler Tablo 2 de sunulmuştur. Tespit edilen ilk görülme yaşları kadınlarda evre 2 de 13, evre 3 ve 4 de 14, evre 5 de 15 ve evre 6 da 16 yaştır. Erkeklerde ise evre 2 ve 3 de 14, evre 4 de 15, evre 5 ve 6 da 16 yaştır.

İntraobserver analiz sonucunda kappa değeri 0.802 olarak tespit edilmiştir. Bu değer iyi bir güvenilirlik sunmaktadır.

\section{Tartışma}

Sol el bileği ve elin adli yaş tayini amacıyla kullanılmasında Greulich ve Pyle (10) ile Tanner metodu (11) en sık kullanılan yöntemler olup, güvenilirliği ve geçerliliği en çok kabul gören yöntemler olarak dikkat çekmektedir. Adli yaş tayinin epifizyal gelişim evrelerine dayanan incelemelerinde modern adli bilimler yaklaşımında epifizyal değerlendirmenin x-ray incelemelere göre daha ayrıntılı değerlendirmesine olanak sağlayan CT ve MR yöntemleri daha fazla önem kazanmaktadır. Adli yaş tayinine ait metodolojik bu gelişim sürecinde aslında daha önceleri de olan ancak özellikle CT kullanımı ile birlikte daha dikkat çekici bir şekilde tartışılan önemli bir konu radyasyon maruziyetidir. Örnek olarak El ve el bileği röntgeni için etkili doz 0,1 microSievert olarak hesaplanmış olup bu doz orthoponthongram için 26 microSievert klavikula CT için ise 600-800 microSievert'tir (38). Özellikle el-el bileğini içeren x-ray uygulamasının kişide yarattığı olası zararlı etkinin göz ardı edilebileceği bazı araştırmacılar tarafindan savunulmaktadır. Ancak klinik amaçlı kullanım dışı uygulamalarda radyasyon maruziyeti ile ilgili çok sayıda etik kaygıyı içeren bildirim de mevcuttur. Özellikle çocuk yaş grubunu da ilgilendirdiği düşünüldüğünde olası kanser riski yetişkine göre daha fazla ve olasılık hesabıyla çok düşük de olsa bulunduğu açıktır. Genel tıp etiği yaklaşımında "öncellikle zarar verme" ilkesi de önemli bir vurgudur. Özellikle çocukların tıbbi değerlendirmelerini konu alan ve iyonize radyasyon ile ilgili tıbbi endikasyonları tartışan güvenlilik ilkesi, zarardan kaçınma, en az invaziv yöntemin tercih edilmesi ve alternatif yöntemlerin tercih edilmesi konusunda önerileri bilinmektedir (39-41) Tüm bu bilgiler doğrultusunda ve ek olarak genel popülasyonda adli amaçlı yaş tayinin ve spesifik olarak sporcularda yaş tayinlerinin tıbbi endikasyon dışı bir uygulama olması nedeniyle günümüz araştırmacılarının non-iyonize teknikler olan USG ve MRI kullanımına dayanan el bileği, diz, ayak bileği, iliak krest alanlarında daha sık araştırmalar yürüttüğü görülmektedir (12-25)

Adli yaş tayini ile ilgili araştırmaların temel önceliklerinin başında yaşın gerçeğe en yakın şekilde tahmin edilebilmesidir. Güncel yöntemler (USG, MRI, CT) çaıışmaları yeni tanımlanan metotları ile güvenilirlik ve

Tablo 2. Evrelere göre minimum and maksimum yaşlar, ortalama $\pm \mathrm{SD}$, alt-üst çeyrekler ile median değerleri

\begin{tabular}{|c|l|l|l|l|l|}
\hline Evre & Cinsiyet & $\mathbf{n}$ & Ortalama \pm SD & Min-Maks & Medyan; LQ; UQ \\
\hline \multirow{2}{*}{1} & Kadın & 21 & $13.48 \pm 1.44$ & $11.5-18.1$ & $13.50 ; 12.85 ; 14.15$ \\
\cline { 2 - 6 } & Erkek & 22 & $13.80 \pm 1.35$ & $12.0-17.8$ & $13.95 ; 12.82 ; 14.37$ \\
\hline \multirow{2}{*}{2} & Kadin & 5 & $14.78 \pm 1.31$ & $13.6-16.9$ & $14.60 ; 13.70 ; 15.95$ \\
\cline { 2 - 6 } & Erkek & 16 & $16.15 \pm 0.84$ & $14.2-17.8$ & $16.00 ; 15.60 ; 16.77$ \\
\hline \multirow{2}{*}{3} & Kadin & 4 & $14.87 \pm 0.62$ & $14.3-15.7$ & $14.75 ; 14.35 ; 15.52$ \\
\cline { 2 - 6 } & Erkek & 9 & $16.73 \pm 1.24$ & $14.4-18.2$ & $16.60 ; 15.90 ; 17.90$ \\
\hline \multirow{2}{*}{4} & Kadin & 17 & $15.92 \pm 1.20$ & $14.2-18.0$ & $15.80 ; 14.80 ; 17.10$ \\
\cline { 2 - 6 } & Erkek & 4 & $17.85 \pm 1.72$ & $15.4-19.4$ & $18.30 ; 16.07 ; 19.17$ \\
\hline \multirow{2}{*}{5} & Kadin & 36 & $17.37 \pm 1.08$ & $15.1-19.7$ & $17.25 ; 16.60 ; 18.17$ \\
\cline { 2 - 6 } & Erkek & 10 & $18.05 \pm 1.06$ & $16.1-19.6$ & $18.15 ; 17.27 ; 18.80$ \\
\hline \multirow{2}{*}{6} & Kadin & 37 & $18.22 \pm 1.08$ & $16.1-20.1$ & $18.30 ; 17.55 ; 19.05$ \\
\cline { 2 - 6 } & Erkek & 17 & $18.10 \pm 0.91$ & $16.8-19.6$ & $17.70 ; 17.50 ; 18.95$ \\
\hline
\end{tabular}


geçerlilik açısından zamana ihtiyaç duymaktadır. Ancak el-el bileği x-ray yöntemleri bugüne kadar çok sayıda çalışmada kontrol edilmiştir. Schmidt ve ark. (42) Greulich ve Pyle'ın metodu için 13-16 yaş arası yaşlar için standart sapmanın 0.3 ile 1.7 yaş arasında olduğunu, TW2 ve TW3 metodları için 13-16 yaş arasında standart sapmanın, TW2 için 04-1.1 yıl ve TW3 için 0.4-1.2 yıl olduğunu belirtmişlerdir. Schmidt ve ark (43) TW2 ve TW3 metodunu 14-16 yaş arasında değerlendirdikleri diğer bir çalışmasında TW2 metodunda ciddi aşırı tahmin riski saptamışlardır (fark -0.1 ve +1.4 yaş arasında idi). Buken ve ark. (44) Türk popülasyonunda farkları GP için yaş gruplarına göre neredeyse tüm yaşlar için ileri (0.17-1.1 yıl) bulduğunu ve kızlar için 11, 12, 14, 16 yaşlarında farkların istatistiksel olarak anlamlı olduğunu bildirmiştir. Aynı çalışmada erkek popülasyonda GP'nin 11-14 yaşlarda geciktiğini, ancak 13 yıl dışında anlamlı olmadığını ve 15-17 yaşlarda ilerde iken, 18-19 yaşlarında geciktiğini bildirmişlerdir. Brezilya popülasyonda TW2 ve TW3 ü değerlendirdiği çalışmasında Ortega (45), TW3 ve TW2 için her iki cinsiyette anlamlı farklar ortaya koymuş, sonuç olarak TW3 sisteminin daha az hata ile Brezilya popülasyonu için uygulanabilir olduğunu göstermiştir.

Çalışmamız normal popülasyonda distal radial epifizin MR metodu ile incelenmesini araştırmaktadır. Sonuçlarımız yaş ve füzyonun derecesinin korelasyonu açısından iyi bir korelasyon olduğunu göstermektedir. $\mathrm{Bu}$ sonuç literatür ile oldukça uyumludur. Dvorak ve ark. (26) yaş ve füzyonun derecesi arasındaki korelasyonu $\mathrm{r}=0.69$ olarak bulunmuştur. Serinelli (32) de iyi bir doğrusal ilişki bildirmiştir (kadınlarda $\mathrm{R}=0.96$ ve erkeklerde $\mathrm{R}=0.94$ ).

Çalışmamızda metodun tekrarlanabilirliği ve güvenilirliği açısından yapılan intraobserver analizler sonucunda iyi sonuçlar elde edilmiştir. Daha önceki çalışmalarda da yüksek güvenilirlik oranları bildirilmektedir. Dvorak ve ark. da (26) inter-rater güvenilirlik (r) 0.91 ile 0.92 arasında bildirilmiştir. Serinelli et al (32) inter-rater uyum için tespit ettikleri Pearson (R) katsayısı 0.98 ve 0.97 olarak bildirilmiştir.

Çalışmamızın metodunu oluşturan Dvorak ve ark. (26) tarafından tanımlanan distal radius epifizin evrelemesi, MR ve projeksiyon radyografi kullanılarak George ve ark. (46) tarafından direkt karşılaştırılmayla analiz edildiğinde metoda özgü tanılar arasında oldukça iyi korelasyon elde edildiği bildirilmiştir. Bu durum MR'ın tanısal yöntem olarak iskelet yaşı tayininde kullanılabileceğini destekler niteliktedir. Ancak önceki çalışmalar ile bu çalışmanın karşılaştırılmasında bazı temel zorluklar vardır. Bunların başında daha ön- ceki çalışmaların genel olarak futbolcularda uygulanmış olmasıdır. Bu durum özellikle bu çalışmalardaki bireylerin yaşını özellikle yanlış bildirme olasılığının bulunması ve gelişimsel olarak yüksek sportif aktiviteye bağlı sekonder gelişimsel özelliklerinin epifizyal gelişime etkisinin sınırlarının belirlenememesi gibi olumsuz faktörleri içermektedir. Aynı zamanda bu ça1ışmalar sadece erkek popülasyon için bilgi sunmaktadır. Bunların dışında Serinelli (32) normal popülasyonda ve her iki cinsiyette çalışmış olsa da değerlendirme yöntemin farklılığ 1 karşılaştırmada yüksek derecede sinırlılık yaratmaktadır.

Adli yaş tayini açısından özellikle metodun kullanılabilirliğini minimal yaşlar üzerinden göstermek önemlidir. Dvorak çalışmalarından evreye özgü minimal yaşları sunmamıştır $(26,27)$. Bu durum Schmidt (33) in çalışmasında çalışma popülasyonunun 18-22 arasında olması açısından kısıtlılık içermektedir. Schmidt (12) diğer bir çalışmasında minimal yaşları evreye özgü sunmuştur ancak bu çalışması distal radial epifizin USG ile değerlendirmesine dayanan 4 evreli bir metodu ele almaktadır. Serinelli'nin (32) çalışmasında da minimal yaş değerlendirmesi verilerine ulaşmak mümkün değildir.

Sonuçlarımız görece kısıtlı sayıda bir popülasyona ait veriler olsa da normal popülasyona ait distal radial epifiz değerlendirme sonuçlarını sunması açısından önemli olabilir. Bu aşamada çalışmanın yapıldığı popülasyonların sosyoekonomik durumlarının da elde edilen verilere etkisi olabileceği unutulmamalıdır $(47,48)$. İntraobserver uyumluluklarımız iyi olsa da uygulayıcı açısından yönteme bağlı deneyimsizliklerin yarattığı hataların da etkinliği gösterildiğinden kısıtlılık olarak hatırlanması gerekir (49).

\section{Sonuç}

Çalışmamız belli bir popülasyona ait non-iyonize bir yöntem olarak MR'ın kullanımına odaklanmıştır. Verilerimizin önceki çalışmalarla kıyaslanmasında - daha önce az sayıda çalışma ve farklı metodolojiler ve popülasyonlar kullanıldığından - zorluklar yaşanmıştır. Mevcut haliyle verilerimiz özellikle 18 yaşı belirlemede Dvorak metodunun yetersiz kalabildiğini göstermektedir. MR bireylerde iyonize radyasyon maruziyetini ortadan kald1ran ve teknik avantajları ile kemik ve kıkırdak dokuyu daha ayrıntılı değerlendirme imkânı sunar. Distal radial epifizin MR ile değerlendirmesinin normal popülasyonda kullanımı için bu alanda daha yüksek sayılı bireyde, daha üst yaşları da kapsayan ve farklı metodolojileri kıyaslayan değerlendirmeler gelecekte Adli Tipta yaş tayininde önemli rol oynayabilir. 


\section{Kaynaklar}

1. Ritz-Timme S, Cattaneo C, Collins MJ, Waite ER, Schutz HW, Kaatsch HJ et al Age estimation: the state of the art in relation to the specific demands of forensic practice. Int J Legal Med 2000;113(3):129-136 doi: 10.1007/s004140050

2. Schmeling A, Grundmann C, Fuhrmann A, Kaatsch HJ, Knell B, Ramsthaler F, Reisinger W, Riepert T, RitzTimme S, Rösing FW, Rötzscher K, Geserick G. Criteria for age estimation in living individuals. Int J Legal Med 2008;122(6):457-60. doi: 10.1007/s00414-008-0254-2

3. Cunha E, Baccino E, Martrille L, Ramsthaler F, Prieto J, Schuliar Y, Lynnerup N, Cattaneo C. The problem of aging human remains and living individuals: a review. For Sci Int 2009;193 (1-3):1-13. doi: 10.1016/j.forsciint.2009.09.008.

4. Schmeling A, Olze A, ReisingerW, Geserick G. Forensic age diagnostics of living people undergoing criminal proceedings. Forensic Sci Int 2004;144(2-3):243-245 doi: 10.1016/j.forsciint.2004.04.059

5. Janes L. Criminal liability of minors and severity of penalties: European trends and developments. Howard League for Penal Reform (England and Wales), 2008. http://www. europeanrights.eu/public/commenti/LauraJanes_en.pdf Accessed: 21 January 2014

6. Jones VF; Committee On Early Childhood, Adoption, And Dependent Care. Comprehensive health evaluation of the newly adopted child. Pediatrics 2012;129(1):e214-23. doi: 10.1542/peds.2011-2381.

7. UNHCR Asylum Trends 2014. Levels and Trends in Industrialized Countries. http://www.unhcr.org/551128679.html Erişim tarihi: 21.06.2016

8. UK Refugees Council. Statistics on Refugees and Asylum (2015). http://www.refugeecouncil.org.uk/assets/0003/5656/Asylum_Statistics_Aug_2015.pdf Erişim tarihi:21.06.2016

9. Schmeling A, Grundmann C, Fuhrmann A, Kaatsch HJ, Knell B, Ramsthaler F, Reisinger W, Riepert T, RitzTimme S, Rösing FW, Rötzscher K, Geserick G. Criteria for age estimation in living individuals. Int J Legal Med 2008;122(6):457-60. doi: 10.1007/s00414-008-0254-2

10. Greulich W, Pyle SI. Radiographic Atlas of Skeletal Development of the Hand and Wrist, 2nd ed., Stanford University Press, Stanford, 1959.

11. Tanner JM, Whitehouse RH, Marshall WA, Healy MJR, Goldstein H . Assessment of Skeletal Maturity and Prediction of Adult Height (TW2 Method), Academic Press, London, 1975.

12. Schmidt S, Schiborr M, Pfeiffer H, Schmeling A, Schulz R. Age dependence of epiphyseal ossification of the distal radius in ultrasound diagnostics. Int. J. Legal Med. 2013;127:831-838. doi: 10.1007/s00414-013-0871-2

13. Schmidt S, Schiborr M, Pfeiffer H, Schmeling A, Schulz R. Sonographic examination of the apophysis of the iliac crest for forensic age estimation in living persons. Sci. Justice 2013;53:395-401. doi: 10.1016/j.scijus.2013.05.004
14. Schulz R, Schiborr M, Pfeiffer H, Schmidt S, Schmeling A. Sonographische Untersuchungen zum zeitlichen Verlauf der Ossifikation der distalen Fibulaepiphyse [Sonographic examination on the time frame of ossification of the distal fibula epiphysis]. Arch. Kriminol. 2013;31:156-165. PMID: 23878894

15. Schulz R, Schiborr M, Pfeiffer H, Schmidt S, Schmeling A. Sonographic assessment of the ossification of the medial clavicular epiphysis in 616 individuals. Forensic Sci. Med. Pathol. 2013;9:351-357. doi: 10.1007/s12024-013-9440-8.

16. Schmidt S, Mühler M, Schmeling A, Reisinger W, Schulz R. Magnetic resonance imaging of the clavicular ossification. Int. J. Legal Med. 2007;21:321-324 doi: 10.1007/ s00414-007-0160-z

17. Tangmose S, Jensen KE, Villa C, Lynnerup N. Forensic age estimation from the clavicle using 1.0T MRI-preliminary results. For. Sci. Int. 2014;234:7-12 doi: 10.1016/j.forsciint.2013.10.027.

18. Hillewig E, Degroote J, Van der Paelt T, Visscher A, Vandemaele P, Lutin B, D'Hooghe L, Vandriessche V, Piette M, Verstraete K. Magnetic resonance imaging of the sternal extremity of the clavicle in forensic age estimation: towards more sound age estimates. Int. J. Legal Med. 2013;127:67789 doi: 10.1007/s00414-012-0798-z

19. Vieth V, Schulz R, Brinkmeier P, Dvorak J, Schmeling A. Age estimation in U-20 football players using 3.0 tesla MRI of the clavicle. For. Sci. Int. 2014;241:118-22. doi: 10.1016/j.forsciint.2014.05.008.

20. Saint-Martin P, Rérolle C, Dedouit F, Bouilleau L, Rousseau H, Rougé D, Telmon N. Age estimation by magnetic resonance imaging of the distal tibial epiphysis and the calcaneum. Int. J. Legal Med. 2013;127:1023-30 doi: 10.1007/ s00414-013-0844-5

21. Saint-Martin P, Rérolle C, Dedouit F, Rousseau H, Rougé D, Telmon N. Evaluation of an automatic method for forensic age estimation by magnetic resonance imaging of the distal tibial epiphysis--a preliminary study focusing on the 18-year threshold. Int. J. Legal Med. 2014;128:675-83. doi: 10.1007/s00414-014-0987-z.

22. Ekizoglu O, Hocaoglu E, Can IO, Inci E, Aksoy S, Bilgili $\mathrm{MG}$. Magnetic resonance imaging of distal tibia and calcaneus for forensic age estimation in living individuals.. Int. J. Legal Med. 2015;129: 825-31. doi: 10.1007/s00414-0151187-1

23. Krämer JA, Schmidt S, Jürgens KU, Lentschig M, Schmeling A, Vieth V. The use of magnetic resonance imaging to examine ossification of the proximal tibial epiphysis for forensic age estimation in living individuals. Forensic Sci. Med. Pathol. 2014;10:306-13. doi: 10.1007/s12024-0149559-2.

24. Dedouit F, Auriol J, Rousseau H, Rougé D, Crubézy E, Telmon N. Age assessment by magnetic resonance imaging of the knee: a preliminary study. For. Sci. Int. 2012;217: e1e7. doi: 10.1016/j.forsciint.2011.11.013 
25. Wittschieber D, Vieth V, Timme M, Dvorak J, Schmeling A. Magnetic resonance imaging of the iliac crest: age estimation in under-20 soccer players. Forensic Sci. Med. Pathol. 2014;10:198-202. doi: 10.1007/s12024-014-9548-5

26. Dvorak J, George J, Junge A, Hodler J. Age determination by magnetic resonance imaging of the wrist in adolescent male football players. Br J Sports Med 2007;41(1):45-52 doi: 10.1136/bjsm.2006.031021

27. Dvorak J, George J, Junge A, Hodler J. Application of MRI of the wrist for age determination in international U-17 soccer competitions. Br J Sports Med 2007;41(8):497-500 doi: 10.1136/bjsm.2006.033431

28. George J, Nagendran J, Azmi K. Comparison study of growth plate fusion using MRI versus plain radiographs as used in age determination for exclusion of overaged football players. Br J Sports Med 2012;46(4):273-278 doi: 10.1136/ bjsm.2010.074948

29. Terada Y, Kono S, Tamada D, Uchiumi T, Kose K, Miyagi R, Yamabe E, Yoshioka H Skeletal age assessment in children using an open compact MRI system. Magn Reson Med 2013;69(6):1697- 1702 doi: 10.1002/mrm.24439

30. Tomei E, Battisti S, Martino M, Nissman D, Semelka RC. Text-atlas of skeletal age determination: MRI of the hand and wrist in children. Wiley-Blackwell, Hoboken,2014.

31. Tomei E, Sartori A, Nissman D, Al Ansari N, Battisti S, Rubini A, Stagnitti A, Martino M, Marini M, Barbato E, Semelka RC. Value of MRI of the hand and the wrist in evaluation of bone age: preliminary results. J Magn Reson Imaging 2014;39(5):1198-1205 doi: 10.1002/jmri.24286

32. Serinelli S, Panebianco V, Martino M, Battisti S, Rodacki K, Marinelli E, Zaccagna F, Semelka RC, Tomei E. Accuracy of MRI skeletal age estimation for subjects 12-19. Potential use for subjects of unknown age. Int J Legal Med 2015;129(3):609-17. doi: 10.1007/s00414-015-1161-y.

33. Schmidt S, Vieth V, Timme M, Dvorak J, Schmeling A. Examination of ossification of the distal radial epiphysis using magnetic resonance imaging. New insights for age estimation in young footballers in FIFA tournaments. Sci Justice 2015;55(2):139-44. doi: 10.1016/j.scijus.2014.12.003.

34. Krämer JA, Schmidt S, Jürgens KU, Lentschig M, Schmeling A, Vieth V. Forensic age estimation in living individuals using 3.0T MRI of the distal femur. Int. J. Legal Med.2014;128:509-14. doi: 10.1007/s00414-014-0967-3

35. 35. Dedouit F, Auriol J, Rousseau H, Rougé D, Crubézy E, Telmon N. Age assessment by magnetic resonance imaging of the knee: a preliminary study. For. Sci. Int. 2012;217:e1-e7. doi: 10.1016/j.forsciint.2011.11.013

36. Saint-Martin P, Rérolle C, Pucheux J, Dedouit F, Telmon N. Contribution of distal femur MRI to the determination of the 18-year limit in forensic age estimation. Int. J. Legal Med. 2014. E-pub ahead of print. doi: 10.1007/s00414-0141020-2

37. Altman DG. Practical statistics for medical research. Chapman \& Hall, New York, 1991.
38. Ramsthaler F, Proschek P, Betz W. How reliable are the risks estimates for X-ray examinations in forensic age estimations? A safety update. Int J Leg Med 2009;123:199-204 doi: 10.1007/s00414-009-0322-2

39. Draft Euratom basic safety standards directive. http:// ec.europa.eu/energy/nuclear/radiation_protection/doc/ art31/2010_02_24_draft_euratom_basic_safety_standards directive.pdf Erişim tarihi: 21.06.2016

40. Separated Children in Europe Programme-Thematic Group on Age Assessment (2011) Review of current laws, policies and practices relating to age assessment in sixteen European Countries. http://www.separated-children-europe-programme.org/publications/reports/Age_Assessment report_review_of_current_policies_and_practice_in_Europe_2011_pdf.pdf Erişism tarihi: 21.06.2016

41. Radiation protection and safety of radiation sources: international basic safety standards - Interim Edition. Vienna. http://www.ilo.org/wcmsp5/groups/public/@ed_protect/@ protrav/@safework/documents/publication/wcms_171036. pdf Erişim tarihi: 21.06.2016

42. Schmidt S, Koch B, Schulz R, Reisinger W, Schmeling A. Studies in use of the Greulich-Pyle skeletal age method to assess criminal liability. Legal Med (Tokyo) 2008;10(4):190 195 doi: 10.1016/j.legalmed.2008.01.003

43. Schmidt S, Nitz I, Schulz R, Schmeling A. Applicability of the skeletal age determination method of Tanner and Whitehouse for forensic age diagnostics. Int J Legal Med 2008;122(4):309-314 doi: 10.1007/s00414-008-0237-3

44. Büken B, Safak AA, Yazici B, Büken E, Mayda AS. Is the assessment of bone age by the Greulich-Pyle meted reliable at forensic age estimation for Turkish children? Forensic Sci Int. 2007;DOI:10.1016/j.forsciint.2007.02.023

45. A.I. Ortega, F. Haiter-Neto, G.M. Ambrosano, F.N. Bo' scolo, S.M. Almeida, M.S. Casanova, Comparison of TW2 and TW3 skeletal age differences in a Brazilian population, J. Appl. Oral Sci. 2006;14(2):142-146 doi: 10.1590/S167877572006000200014

46. J. George, J. Nagendran, K. Azmi, Comparison study of growth plate fusion usingMRI versus plain radiographs as used in age determination for exclusion of overaged football players, Br. J. Sports Med. 2012;46:273-278.

47. Schmeling A, Reisinger W, Loreck D, Vendura K, Markus W, Geserick G. Effects of ethnicity on skeletal maturation:consequences for forensic age estimations. Int J Leg Med 2000;113: 253-258 doi: 10.1007/s004149900102

48. Schmeling A, Olze A, Reisinger W, Geserick G. Forensic age estimation and ethnicity. Leg Med 2005;7:134-137 doi: 10.1016/j.legalmed.2004.07.004

49. Wittschieber D, Schulz R, Vieth V, Küppers M, Bajanowski T, Ramsthaler F, Püschel K, Pfeiffer H, Schmidt S, Schmeling A. Influence of the examiner's qualification and sources of error during stage determination of the medial clavicular epiphysis by means of computed tomography. Int J Legal Med. 2014;128(1):183-91. doi: 10.1007/s00414-013-0932-6. 